\title{
GENERALIZED MORPHEA: A CASE REPORT
}

\author{
Valentina Dimitrova, Ivelina Yordanova, Dimitar Gospodinov \\ Department of Dermatology and Venereology, \\ Medical University - Pleven, Bulgaria
}

\section{ABSTRACT}

Generalized morphea is a subtype of localized scleroderma, which lacks systemic manifestations and displays widespread, multiple, well-circumscribed, indurated plaques.

We represent a 46-year-old woman with generalized morphea. More than 3 years ago she developed multiple, nonpruritic plaques symmetrically on the trunk and extremities.

The patient's clinical history, laboratory analysis and histopathologic examination were consistent with generalized morphea, a rare subtype of localized scleroderma.

Key words: localized scleroderma, morphea, generalized morphea

\section{INTRODUCTION}

Localized scleroderma (morphea) is a cutaneous limited fibrosis and represents a wide variety of clinical entities. Based on clinical morphologic findings, morphea can be classified into five groups: plaque, generalized, bullouse, linear, and deep. Generalized morphea is a rare subtype of localized scleroderma and displays widespread, multiple, well-circumscribed, indurated plaques that resemble the lesions of the plaque form.

Like all other forms of scleroderma, that's a disease of unknown etiology but may involve an autoimmune etiology and affects both the microvasculature and the loose connective tissue.

\section{Case report}

History.

A 46-year-old woman is presented with a 3-year history of dermatosis involving the trunk and extremiteties.

More than 3 years ago she developed multiple nonpruritic plaques.

The disease began as a discrete area of erythema and progressed steadily with induration of the plaques and affection of other body areas. The surface became smooth and shiny. Some of the lesions were directly preceded by local trauma (subcutaneous injections).

The patient denies systemic complaints and a family history of a similar illness

\section{Physical examination.}

Physical examination revealed multiple, hyper-, hypopigmented and ivory-colored indurated plaques with atrophic, shiny surface on the upper and lower extremities, trunk, and buttocks. The lesions ranged from $1 \mathrm{~cm}$ to $30 \mathrm{~cm}$ in diameter and some of them were surrounded by violaceous border (lilac ring).

\section{Laboratory data.}

The complete blood count with differential analysis, liver function tests, chemistry panel, and urinalysis were normal.

Antinuclear antibodies, anti-Scl-70 antibodies, and the antibodies against Borrelia burgdorferi were negative. $\mathrm{X}$-rays showed that the lungs were not affected.

\section{Histopathology.}

The skin biopsy showed an epidermal atrophy, a sparse superficial and predominantly deep dermal and subcutaneous perivascular infiltrate of lymphocytes and plasma cells, and the collagen bundles appeared thickened and closely packed with paucity of adnexal structures.

\section{Diagnosis.}

The patient's clinical history, laboratory analysis and histopathologic examination were consistent with generalized morphea, a rare subtype of localized scleroderma.

\section{Differentials.}

Systemic sclerosis (PSS, CREST), Acrodermatitis chronica atrophicans, Atrophoderma idiopatica progressiva, Lichen sclerosus et atrophicus, Sclerodermalike skin changes in systemic disease, Chemically induced dermal fibrosis (drugs, chemicals).

\section{Treatment.}

The patient was treated periodically with Penicillin G, Retarpen and local glucocorticoids. Additionally, physical therapy has been used concomitantly with the systemic medications. 


\section{DISCUSSION}

In 1752 Carlo Curzio offered the first detailed description of a patient affected by thickened skin. Much later in 1836 Giovambattista Fantonetti applied the term scleroderma to the conditions similar to that described by Curzio.

Currently the scleroderma is a broad term encompassing both localized and systemic sclerosis.

Localized scleroderma (morphea) represents a wide variety of clinical entities which on the opposite end of the scleroderma spectrum compared with systemic sclerosis.

Peterson et al. divide morphea into five categories: plaque, generalized, bullouse, linear, and deep. This classification is based on the morphologic findings and simplify the diagnostic and therapeutic approach /4, 5/.

Generalized morphea represents a rare subtype of the disease, which ranges from 3 up to $13 \%$ of all cases. The patients are classified as having generalized morphea when they have four or more lesions on at least two areas of the body $/ 6 /$.

These multiple lesions resemble the lesions of the plaque form - weel-circumscribed indurated plaques that range from $1 \mathrm{~cm}$ to more than $20 \mathrm{~cm}$ in diameter. In the active phase of the disease a violaceous border (lilac ring) may surround the indurated region. With disease progression sclerosis develops centrally as the lesion undergoes peripheral expansion. The plaques of generalized morphea are often hyperpigmented to silvery.

The etiology of the disease is unknown. Some morphea patients report a history of local trauma directly preceding the onset of the disease.

There has been a debate about a possible association between Borrelia burgdorferi and morphea. This association shows geographic and genospecific differences. In Europe and Asia, serological detection of antibodies against Borrelia burgdorferi was described in $0-60 \%$ of the patients with morphea and in $19 \%$ in the U.S.A. $/ 3,8 /$.

A retrospective study of Borrelia DNA suggests that morphea in Germany and Japan can be related with European genotypes of Borrelia /3, 8/.

Overproduction of collagen by fibroblasts in affected tissues is common for all forms of morphea, although the mechanism by which these fibroblasts are activated is unknown. Autoimmune etiology is discussed.

Serum autoantibodies are commonly present in all types of morphea.

Antinuclear antibodies are present in approximately $50 \%$ of morphea patients, typically with a homogeneous pattern.
Antihiston antibodies (AHA) are detected in $42 \%$ of patients with localized scleroderma, and in $87 \%$ of patients with generalized morphea $/ 7 /$. The presence of AHA is strongly correlated with the total number of lesions and the number of involved areas of the body.

The presence of AHA in patients with morphea is correlated with that of anti-single-stranded DNA antibodies.

Anti-ssDNA antibodies are presented in $25 \%$ of patients with plaque-type morphea, in $75 \%$ of those with generalized morphea, and in $50 \%$ of those with linear morphea and these antibodies correlate with the extension and the activity of the disease, too.

Anticentromere, anti-Sc170, and anti-doublestranded DNA antibodies are present in less than 5\% of morphea patients.

In our case antinuclear antibodies, anti-Scl-70 antibodies, and the antibodies to Borrelia burgdorferi were negative.

Peripheral eosinophilia may occur in localized scleroderma and indicates active illness, but that was not detected in our case.

The treatment of generalized morphea is challenging. High-potency topical glucocorticoids may be applied locally. Systemic glucocorticoids, antimalarials, colchicines, and azathioprine are usually ineffective. Dpenicillamine $(2-5 \mathrm{mg} / \mathrm{kg})$ may halt the formation of new lesions and induce the softening of the older lesions $/ 2 /$. Oral calcitriol (0.50-0.75 $\mathrm{mg}$ daily) may improve skin extensibility in adult patients with generalized morphea / 1/. UVA1 (340-450nm) phototherapy may also be helpful. Finally, oral methotrexate (15-25 mg per week) may provide some benefit to a subset of patients.

Our patient was treated with Penicillin G 10UI daily for 10 days, Retrpen 2,4 UI per week for 2 months, and with phototherapy. As a result of this treatment the lesions became softer.

\section{CONCLUSION}

In conclusion the case presented shows the typical clinical and histology features of one of the rarest subtypes of localized scleroderma - generalized morphea. 


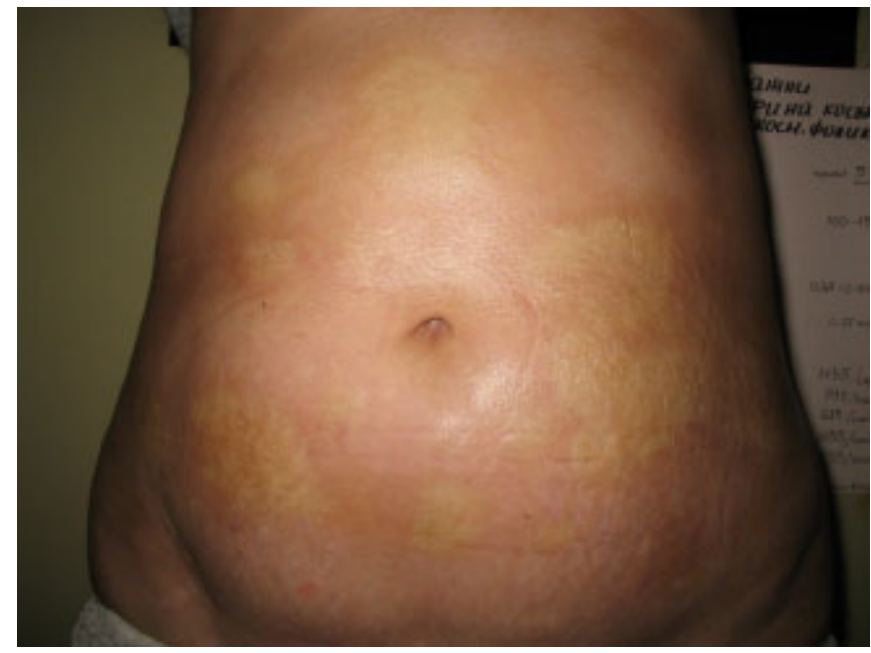

Fig. 1., Fig. 2. Multiple, hyper-, hypopigmented and ivory-colored indurated plaques with atrophic, shiny surface on the trunk and lower extremities.
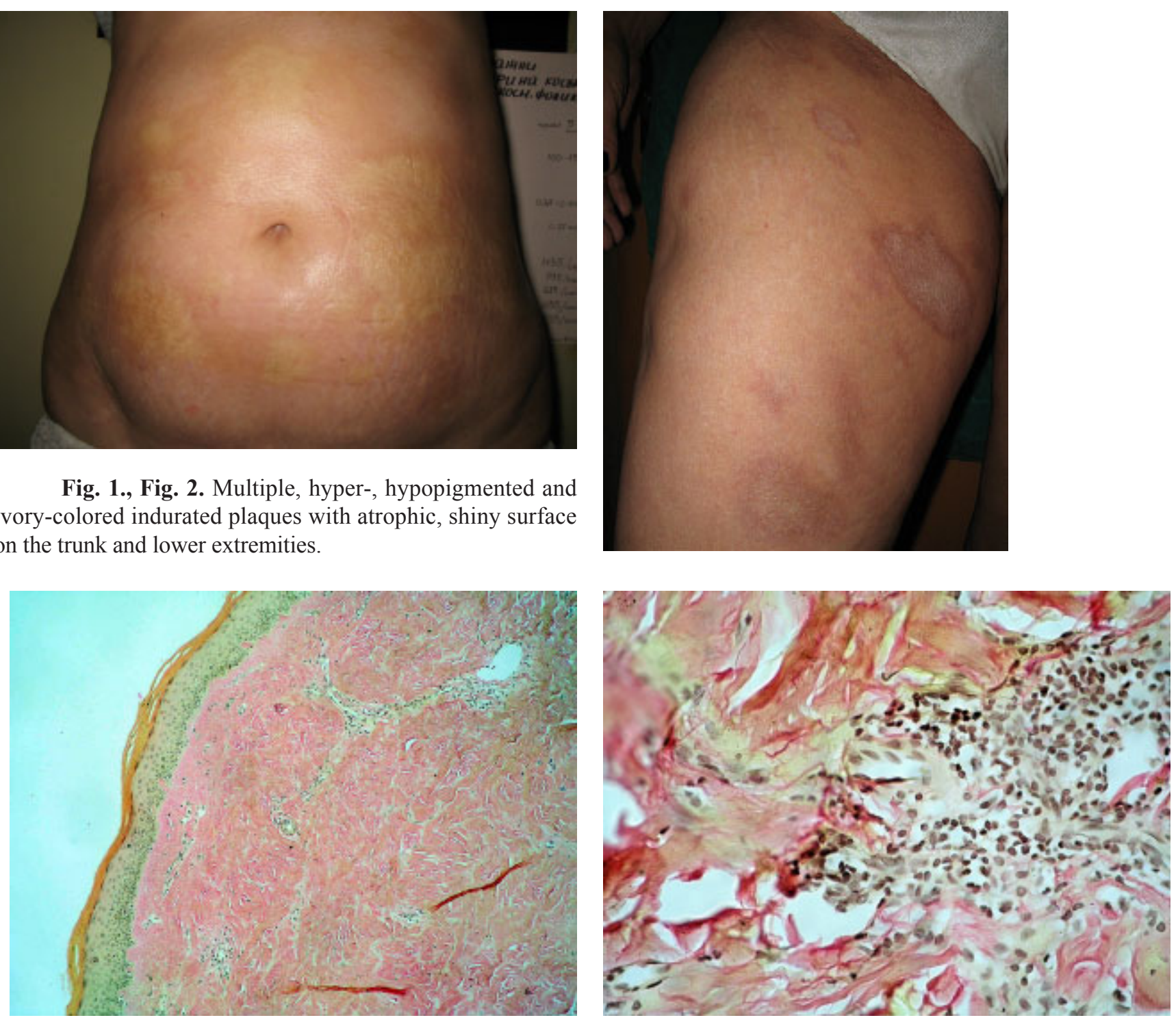

Fig. 3a, 3b. Epidermal atrophy, superficial and deep dermal perivascular infiltrate of lymphocytes and plasma cells. The collagen bundles are thickened and closely packed $/ 3 \mathrm{a} \times 10,3 \mathrm{~b} \times 100 /$.

\section{REFERENCES}

1. Cunningham BB, Landells ID et al. Topical calcipotriene for morphea/linear scleroderma. J Am Acad Dermatol 1998; 39: 211-5.

2. Falanga V, Medsger TA Jr. Dpenicillamine in the treatment of localized scleroderma. Arch Dermatol 1990; 126: 661-4.

3. Fujiwara $\mathrm{H}$, Fujiwara $\mathrm{K}$ et al. Detection of Borrelia burgdorferi DNA (B garinii or $b$ afzelii) in morphea and lichen sclerosus et atrophicus tissues of German and Japanese but not of US patients. Arch dermatol 1997; $133: 41-4$.

4. Mayes MD. Classification and epidemiology of scleroderma. Semin Cutan Med Surg 1998; 17: 22-6.

5. Peterson LS, Nelson AM, Su WP. Classification of morphea (localized scleroderma). Mayo Clin Proc 1995; 70: 1068-76.

6. Sato S, Fujimoto M, Ihn H, Kikuchi
K, Takehara K. Clinical characteristics associated with antihistone antibodies in patients with localized scleroderma. J Am Acad Dermatol 1994; 31: 567-71.

7. Sato S, Ihn H, Soma Y et al. Antihiston antibodies in patients with localized scleroderma. Arthritis Rheum 1993; 36: 1137-41.

8. Weide $\mathrm{B}$ et al. Is morphoea caused by Borrelia burgdorferi? A review. Br J Dermatol 2000; 142: 636.

Address for correspondence: Dr. Valentina Dimitrova,

Department of Dermatology and Venereology, Medical University Pleven, 91, General Vladimir Vasov Str., 5800 Pleven, Bulgaria; Tel./fax: +359(64)886 622; E-mail: enti_bg@yahoo.com; 